Check for updates

Cite this: RSC Adv., 2017, 7, 18366

\title{
Bose-Einstein oscillators and the excitation mechanism of free excitons in 2D layered organic- inorganic perovskites
}

\author{
Bo Peng, (D) *a Jian Li, ${ }^{\text {a }}$ Qi Li, ${ }^{a}$ Yue Li, ${ }^{a}$ Hai Zhu, ${ }^{b} \mathrm{Li}_{\text {Zhang, }}{ }^{a}$ Xin Wang, ${ }^{a} \mathrm{Lei} \mathrm{Bi}{ }^{a}$ \\ Haipeng Lu, ${ }^{a}$ Jianliang Xie, ${ }^{a}$ Longjiang Deng, ${ }^{\star a}$ Qinghua $\mathrm{Xu}^{\star \mathrm{b}}$ and Kianping Loh ${ }^{\star b}$
}

Following intense research on two-dimensional (2D) materials, there has been a resurgence of interest in 2D layered hybrid organic-inorganic perovskites. These 2D perovskites have direct band gaps regardless of their thickness. Excitons are confined to monolayers because of the materials' selforganized quantum-well electronic structure. Gaining insight into the exciton dynamics is central to understanding the light-matter interactions in 2D organic-inorganic perovskites. Herein, we investigate the free-exciton dynamics in $2 \mathrm{D}$ layered $\mathrm{CH}_{3}\left(\mathrm{CH}_{2}\right)_{3} \mathrm{NH}_{3} \mathrm{Pbl}_{4}$ perovskite, demonstrating an anomalous temperature variation of the photoluminescence $(\mathrm{PL})$ energy, which deviates from the conventional Varshni formula and is consistent with the behaviour of Bose-Einstein oscillators. The acoustic phonons induced by the coherent lattice motion of the atoms result in a positive temperature variation. Two-pulse emission modulation measurements reveal the excitation mechanism of the strong two-photon $\mathrm{PL}$ in $\mathrm{CH}_{3}\left(\mathrm{CH}_{2}\right)_{3} \mathrm{NH}_{3} \mathrm{Pbl}_{4}$ perovskite, in which two photons are simultaneously absorbed through a virtual state.

Received 24th February 2017

Accepted 20th March 2017

DOI: $10.1039 / c 7 r a 02308 a$

rsc.li/rsc-advances
Nonetheless, ultra-thin single-crystal $\mathrm{CH}_{3} \mathrm{NH}_{3} \mathrm{PbI}_{4}$ with a single unit cell of $\sim 1.3 \mathrm{~nm}$ in thickness has recently been synthesized, ${ }^{22}$ and its photoluminescence (PL) peaks were found to exhibit a surprising dependence on the flake thickness.

The crystal geometries of organic-inorganic hybrid $\mathrm{R}\left(\mathrm{CH}_{2}\right)$ ${ }_{n} \mathrm{NH}_{3} \mathrm{MX}_{m}$ perovskites depend on the tolerance factor $t$, defined as $t=\sqrt{2}\left(R_{\mathrm{M}}+R_{\mathrm{X}}\right) /\left(R_{\mathrm{R}\left(\mathrm{CH}_{2}\right) n \mathrm{NH}_{3}}+R_{\mathrm{X}}\right)$, where $R_{\mathrm{R}\left(\mathrm{CH}_{2}\right) n \mathrm{NH}_{3}}, R_{\mathrm{M}}$ and $R_{\mathrm{X}}$ are the ionic radii of the corresponding substances. In the case that the radii of the organic chain are larger than that of propylamine, an organic-inorganic hybrid $\mathrm{R}\left(\mathrm{CH}_{2}\right)_{n} \mathrm{NH}_{3} \mathrm{MX}_{4}$ perovskite will adopt a $2 \mathrm{D}$ layered structure. ${ }^{23}$ Hence, there are on-going efforts to develop 2D layered perovskites in the form of $\mathrm{R}\left(\mathrm{CH}_{2}\right)_{n} \mathrm{NH}_{3} \mathrm{MX}_{4}$ monolayers. Such $2 \mathrm{D}$ layered organic-inorganic halide $\mathrm{R}\left(\mathrm{CH}_{2}\right)_{n} \mathrm{NH}_{3} \mathrm{PbX}_{4}$ perovskite materials exhibit a self-organized quantum-well electronic structure (Fig. 1a), consisting of alternating $\sim 0.6 \mathrm{~nm}$ inorganic layers and $\sim 1 \mathrm{~nm}$ organic layers. $^{24-26}$ They exhibit strong solar absorption, large exciton binding energies and small Bohr radii, which endow these $\mathrm{R}\left(\mathrm{CH}_{2}\right)_{n} \mathrm{NH}_{3} \mathrm{PbX}_{4}$ materials with excellent optical properties, such as sharp resonant emission with a narrow full width at half maximum (FWHM) and a high quantum yield. ${ }^{27}$ Previous reports have demonstrated that the PL peaks of $\mathrm{R}\left(\mathrm{CH}_{2}\right)_{n} \mathrm{NH}_{3}-$ $\mathrm{MX}_{4}$ perovskites can be tuned within the visible-infrared range by adjusting the organic component, R; the metal cation, $\mathrm{M}(\mathrm{M}$ $=\mathrm{Pb}, \mathrm{Sn}, \mathrm{Ge})$; and the halide, $\mathrm{X}(\mathrm{X}=\mathrm{I}, \mathrm{Br}, \mathrm{Cl}) \cdot{ }^{28-30}$ Recently, single- and few-layer $\left(\mathrm{C}_{4} \mathrm{H}_{9} \mathrm{NH}_{3}\right)_{2} \mathrm{PbBr}_{4}$ single-crystalline perovskite squares have been successfully prepared via a solution-
${ }^{a}$ National Engineering Research Centre of Electromagnetic Radiation Control Materials, State Key Laboratory of Electronic Thin Films and Integrated Devices, School of Microelectronics and Solid State Electronics, University of Electronic Science and Technology of China, Chengdu 610054, China.E-mail: bo_peng@uestc. edu.cn; denglj@uestc.edu.cn

${ }^{b}$ Department of Chemistry, Centre for Advanced 2D Materials and Graphene Research Centre, National University of Singapore, 3 Science Drive 3, Singapore 117543. E-mail: chmxqh@nus.edu.sg; chmlohkp@nus.edu.sg 
a

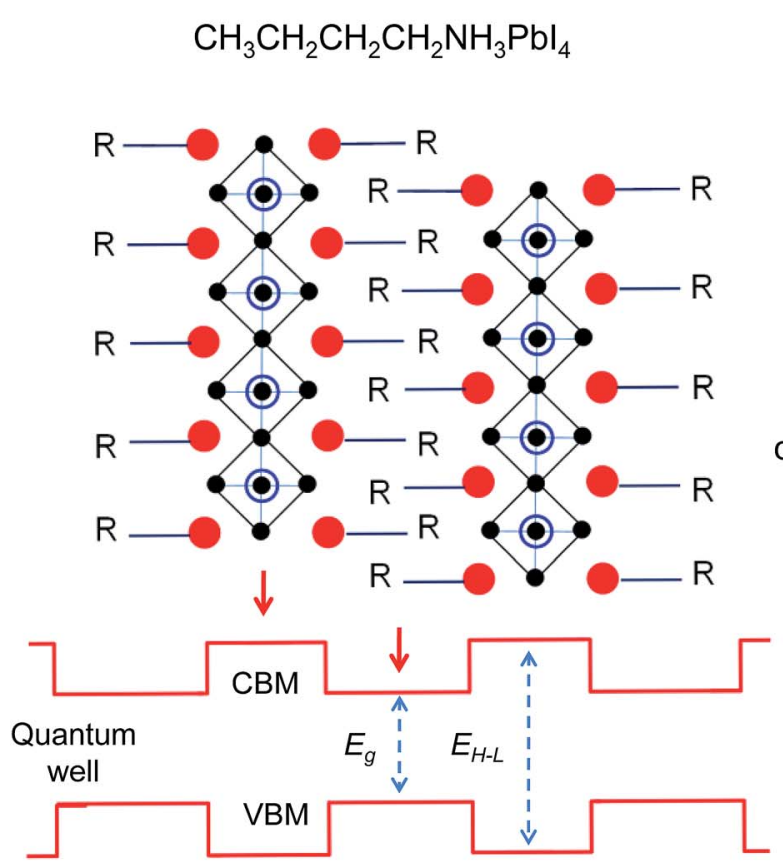

b
C

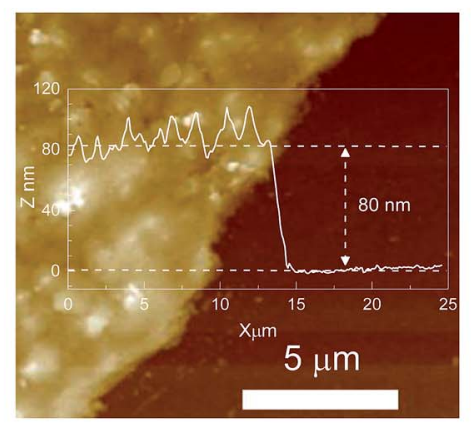

$192.7 \mathrm{~nm}$

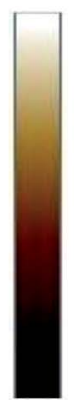

$-168.7 \mathrm{~nm}$

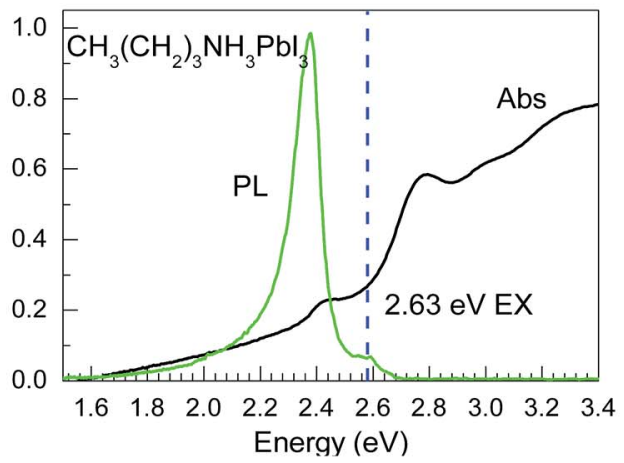

Fig. 1 (a) Schematic illustration of $2 \mathrm{D}$ layered $\mathrm{CH}_{3} \mathrm{CH}_{2} \mathrm{CH}_{2} \mathrm{CH}_{2} \mathrm{NH}_{3} \mathrm{Pbl}_{4}$ perovskite and its quantum-well electronic structures. (b) AFM image of a $\mathrm{CH}_{3} \mathrm{CH}_{2} \mathrm{CH}_{2} \mathrm{CH}_{2} \mathrm{NH}_{3} \mathrm{Pbl}_{4}$ perovskite film spin coated on quartz. (c) Absorption and photoluminescence spectra of the 2D perovskite at room temperature.

phase growth method. The optical band gap of the 2D square sheets was found to be slightly blue-shifted by $40 \mathrm{meV}$ compared with that of the bulk crystal, but it was otherwise nearly indistinguishable for configurations ranging from 1 to 22 layers. ${ }^{23}$ In addition, mechanical exfoliation has been applied to produce $2 \mathrm{D}$ few-layer $\left(\mathrm{C}_{6} \mathrm{H}_{5} \mathrm{C}_{2} \mathrm{H}_{4} \mathrm{NH}_{3}\right)_{2} \mathrm{PbI}_{4}$ perovskites, in which strong anti-Stokes PL results in laser cooling by $\sim 58.7 \mathrm{~K}^{31}$ However, the nature of the excitons in $2 \mathrm{D}$ layered $\mathrm{R}\left(\mathrm{CH}_{2}\right)_{n} \mathrm{NH}_{3} \mathrm{MX}_{4}$ perovskites is still not well understood.

Herein, we investigate the exciton dynamics in $2 \mathrm{D}$ layered $\mathrm{CH}_{3}\left(\mathrm{CH}_{2}\right)_{3} \mathrm{NH}_{3} \mathrm{PbI}_{4}$ perovskite in the range of $10-300 \mathrm{~K}$ by means of PL spectroscopy and two-pulse emission modulation (TPEM) spectroscopy. Interestingly, we find that the variation of the PL peak energy as a function of temperature deviates from Varshni's empirical expression; the phase transition occurs in the range of $200-250 \mathrm{~K}$. Below $200 \mathrm{~K}$, the band gap energy first increases to a maximum of $\sim 2.374 \mathrm{eV}$ at $150 \mathrm{~K}$ but then monotonically drops to $\sim 2.364 \mathrm{eV}$ at $13 \mathrm{~K}$ as the temperature decreases. We demonstrate that Bose-Einstein oscillation contributes to the positive temperature variation of the PL peak energy as a result of free excitons. We also investigate the excitation mechanism of two-photon photoluminescence (TPPL), in which two photons are simultaneously absorbed through a virtual state to excite a single electronic transition. Our work reveals the mechanisms underlying exciton dynamics and excitation in $2 \mathrm{D}$ perovskites.

\section{Experiment}

\section{$\mathrm{CH}_{3}\left(\mathrm{CH}_{2}\right)_{3} \mathrm{NH}_{3} \mathrm{I}$ synthesis and film preparation}

$\mathrm{CH}_{3}\left(\mathrm{CH}_{2}\right)_{3} \mathrm{NH}_{3} \mathrm{I}$ was synthesized using the reported method. ${ }^{32}$ Briefly, $1.5 \mathrm{~mL}$ of $\mathrm{CH}_{3}\left(\mathrm{CH}_{2}\right)_{3} \mathrm{NH}_{2}$ was added to $50 \mathrm{~mL}$ of ethanol under Ar gas and stirred for $30 \mathrm{~min}$ at $0{ }^{\circ} \mathrm{C}$. Subsequently, $1 \mathrm{~mL}$ of hydroiodic acid ( $55 \mathrm{wt} \%$ in water, Sigma-Aldrich) was added. The mixed solution was stirred for a further $2 \mathrm{~h}$. The white raw product $\mathrm{CH}_{3}\left(\mathrm{CH}_{2}\right)_{3} \mathrm{NH}_{3} \mathrm{I}$ was obtained through rotary evaporation at $50{ }^{\circ} \mathrm{C}$, washed three times with diethyl ether, and then finally recrystallized from a mixed solvent of diethyl ether and ethanol. The white solid was dried in vacuum for $24 \mathrm{~h}$ and stored in a glovebox. Then, $138 \mathrm{mg}$ of $\mathrm{PbI}_{2}$ and $105 \mathrm{mg}$ of $\mathrm{CH}_{3}\left(\mathrm{CH}_{2}\right)_{3} \mathrm{NH}_{3} \mathrm{I}$ were dissolved in $2.31 \mathrm{~mL}$ of DMF. A volume of $20 \mu \mathrm{L}$ of the mixed solution was spin coated onto quartz with dimensions of $1 \times 1 \mathrm{~cm}^{2}$ at $2000 \mathrm{rpm}$ for $2 \mathrm{~min}$, and the samples were then placed in vacuum for $24 \mathrm{~h}$ for the removal of residual DMF solvent.

\section{TPPL measurements}

The TPPL spectra were measured using a home-built twophoton optical microscope. A mode-locked Ti:sapphire oscillator (TiF-100M, Avesta) was used as the excitation source, generating $80 \mathrm{fs}$ pulses with a central wavelength of $785 \mathrm{~nm}$ and repetition rate of $84.5 \mathrm{MHz}$. The laser beam was passed through a 785/10 nm band-pass filter (LD01-785/10-25, Semrock), 5× 
spatially expanded, and then reflected by a 50/50 beam splitter to the objective lens $(\mathrm{NA}=0.5)$. The emission signals were collected by the same objective lens and filtered with two $785 \mathrm{~nm}$ notch filters (NF03-785E-25, Semrock) to reduce laser scattering and with a long-pass filter with a cut-off wavelength of $450 \mathrm{~nm}$ (Chroma) to remove the second-harmonic generation signal. The spectra of the emission signals were measured using a monochromator (Acton SpectraPro 2300i, Princeton Instruments) coupled to a CCD (Pixis 100B, Princeton Instruments) via an optical fibre.

\section{TPEM measurements}

Two-pulse correlation measurements were performed using a dual-channel regenerative amplifier (ORPHEUS Twins, Light Conversion) pumped by a femtosecond laser oscillator (PHAROS, Light Conversion). This system provided laser pulses centred at $800 \mathrm{~nm}$, with a pulse duration of $200 \mathrm{fs}$ and a repetition rate of $1 \mathrm{MHz}$. The laser beam was split into two pulse replicas. The two laser pulses were spatially overlapped and focused by an objective $(\times 20)$ onto the $2 \mathrm{D}$ perovskite thin film (the laser pulses were broadened to $\sim 330$ fs after the objective). The TPPL of the $2 \mathrm{D}$ perovskite thin film was collected using the same objective and detected by a photomultiplier tube (E717-63, Hamamatsu). The emission was filtered using a $550 \mathrm{~nm} \pm$ $50 \mathrm{~nm}$ band-pass filter and a $700 \mathrm{~nm}$ short-pass filters. The twopulse correlation curve was obtained by varying the time delays between the two pulse replicas through a translational stage (MILS250HA, Newport).

\section{UV-vis absorption, PL, and AFM measurements}

UV-vis absorption data for $\mathrm{CH}_{3}\left(\mathrm{CH}_{2}\right)_{3} \mathrm{NH}_{3} \mathrm{PbI}_{4}$ were obtained using a PerkinElmer LAMBDA 750 spectrophotometer. The steady-state PL signal was recorded using a Witec Alpha 300R confocal Raman microscope under $0.67 \mathrm{~mW}$ laser excitation at $4.88 \mathrm{eV}$. The samples were placed in a closed-cycle cryogenic system for low-temperature measurements over a range of 10$300 \mathrm{~K}$. The AFM data were recorded using a BRUKER Dimension FastScan system.

\section{Results and discussion}

$\mathrm{CH}_{3}\left(\mathrm{CH}_{2}\right)_{3} \mathrm{NH}_{3} \mathrm{I}$ was synthesized through the reaction of $\mathrm{CH}_{3}$ $\left(\mathrm{CH}_{2}\right)_{3} \mathrm{NH}_{3}$ and $\mathrm{HI}$ at $0{ }^{\circ} \mathrm{C}$ for $2 \mathrm{~h}$ and was then dissolved in dimethylformamide (DMF) with $\mathrm{PbI}_{2}(10 \% \mathrm{wt})$. The as-grown crystallites were spin coated onto quartz at $2000 \mathrm{rpm}$ for $2 \mathrm{~min}$, and then dried under vacuum for $24 \mathrm{~h}$. An AFM image shows that the thickness of the $2 \mathrm{D}$ layered $\mathrm{CH}_{3}\left(\mathrm{CH}_{2}\right)_{3} \mathrm{NH}_{3} \mathrm{PbI}_{4}$ films was $\sim 80 \mathrm{~nm}$ (Fig. 1b). Fig. 1c displays the absorption and PL spectra measured for the prepared 2D perovskite films at room temperature. Two obvious absorption features are evident at $\sim 2.79$ and $\sim 2.43 \mathrm{eV}$, which are assigned as the band-edge peak and the free-exciton peak, ${ }^{24,30}$ respectively. Intrinsic freeexciton recombination dominates the PL emission, resulting in a strong PL peak at $\sim 2.38 \mathrm{eV}$ under laser excitation at $2.63 \mathrm{eV}$ (Fig. 1c).
To further clarify the underlying dynamics responsible for the evolution of the free-exciton emission, we plot the evolution of the excitonic energy (normalized PL) as a function of the temperature from 13 to $300 \mathrm{~K}$ under laser excitation at $4.88 \mathrm{eV}$, as shown in Fig. 2a. Surprisingly, an anomalous non-monotonic relationship between the PL peak energy and temperature is observed for the 2D layered $\mathrm{CH}_{3}\left(\mathrm{CH}_{2}\right)_{3} \mathrm{NH}_{3} \mathrm{PbI}_{4}$ films. As the temperature decreases from room temperature, the PL peak energy first increases from $\sim 2.367 \mathrm{eV}$ to a maximum of $\sim 2.375 \mathrm{eV}$ at $230 \mathrm{~K}$, however sharply drops to $\sim 2.373 \mathrm{eV}$ at 200 $\mathrm{K}$, which further increases to $\sim 2.374 \mathrm{eV}$ at $150 \mathrm{~K}$ and then monotonically decreases to $\sim 2.364 \mathrm{eV}$ at $13 \mathrm{~K}$ (Fig. 2b). Typically, the PL peak energy monotonically increases as the temperature decreases, as expressed by the Varshni model: $:^{33}$

$$
E_{\mathrm{g}}(T)=E_{0}+\frac{\alpha T^{2}}{T-\beta},
$$

where $T$ is the temperature; $E_{\mathrm{g}}(T)$ and $E_{0}$ are the fundamental free-exciton emission energies at $T$ and $0 \mathrm{~K}$, respectively; and $\alpha$ and $\beta$ are constants. A monotonic increase in the PL peak energy as the temperature decreases has been observed in many semiconductor materials, such as GaN, InGaAs, $\mathrm{MoS}_{2}, \mathrm{MoSe}_{2}$, and CdS. ${ }^{34-38}$ However, the Varshni model is not applicable for our experimental data. The PL peak energy increase to a maximum at $\sim 230 \mathrm{~K}$ as the temperature decreases, however, which is similar in the range of $\sim 230-205 \mathrm{~K}$, and drops sharply at $200 \mathrm{~K}$. The full width at half maximum (FWHM) also show a distinct and sharp variation at $\sim 150 \mathrm{~K}$, which decreases as the temperature decrease in the range of 300-150 K, however, become similar below $150 \mathrm{~K}$ (the inset in Fig. $2 \mathrm{~b}$ ). ${ }^{39}$ We assign this behaviour to a phase transition of the perovskite crystal, which have been observed in the 3D and 2D organic-inorganic hybrid perovskites. ${ }^{\mathbf{4 0 4 1}}$ It should be noted that the experimental results cannot be fitted by Varshni model above $205 \mathrm{~K}$, because the two phases coexist within this temperature range. Surprisingly, below $200 \mathrm{~K}$, the PL peak energy first achieves a maximum of $2.374 \mathrm{eV}$ at $150 \mathrm{~K}$ and then monotonically decreases to $2.364 \mathrm{eV}$ as the temperature decrease.

Generally, the temperature variation of the PL peak energy has its origins in the effects of lattice thermal expansion (TE) and electron-phonon interaction (EP), which, at constant temperature, can be expressed as follows: ${ }^{42}$

$$
\left(\Delta E_{0}\right)_{T}=\left(\Delta E_{0}\right)_{\mathrm{EP}}+\left(\Delta E_{0}\right)_{\mathrm{TE}}
$$

$\left(\Delta E_{0}\right)_{\mathrm{TE}}$ represents the harmonic corrections to the crystal volume at low temperatures, which can be related to the isotope masses through the zero-point vibrational amplitudes, $\left(\partial E_{0} / \partial M_{\mathrm{k}}\right)_{\mathrm{TE}} \cdot\left(\Delta E_{0}\right)_{\mathrm{TE}}$ is usually much smaller than $\left(\Delta E_{0}\right)_{\mathrm{EP}}$; thus, it is justifiable to neglect $\left(\Delta E_{0}\right)_{\mathrm{TE}}$ at low temperatures. ${ }^{43,44} \mathrm{We}$ focus on investigating the exciton dynamics below $200 \mathrm{~K}$, and suggest that the renormalization of the band gap and PL emission stems from electron-phonon interactions that occur below $200 \mathrm{~K}$. In 2D layered perovskites, the valence bands (VBs) consist mainly of the $\mathrm{Pb}(6 s)^{2}$ and $\mathrm{I}(5 \mathrm{p})^{6}$ orbitals, and the conduction band (CB) is mainly composed of the $\mathrm{Pb}(6 \mathrm{~s})(6 \mathrm{p})$ orbital. $^{45,46}$ The organic component does not play a significant 
a

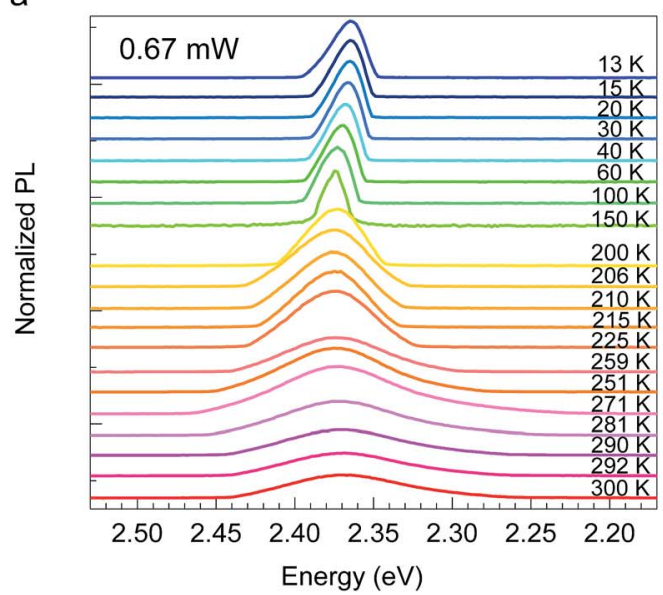

C

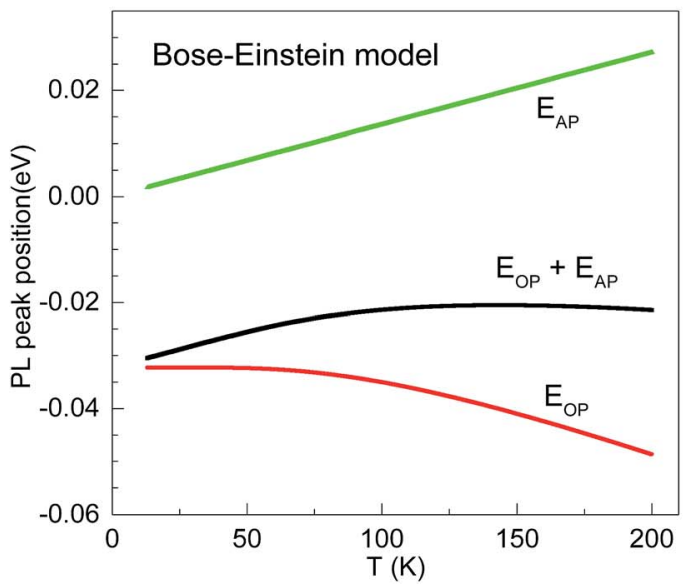

b

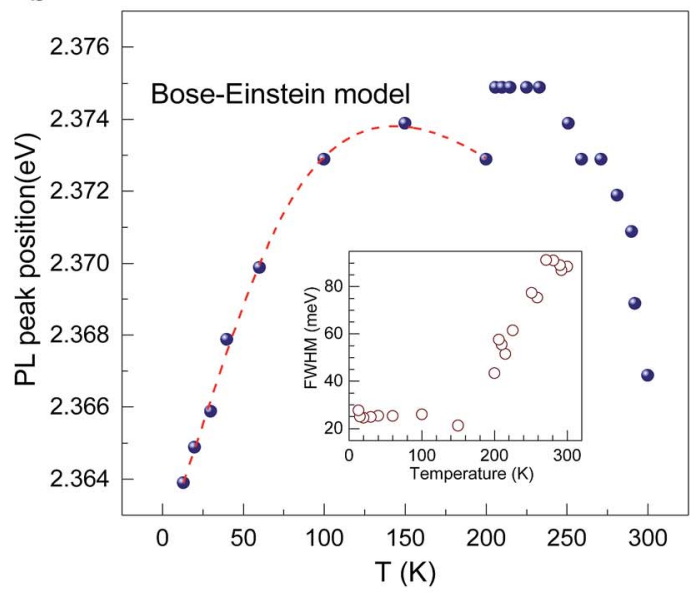

d

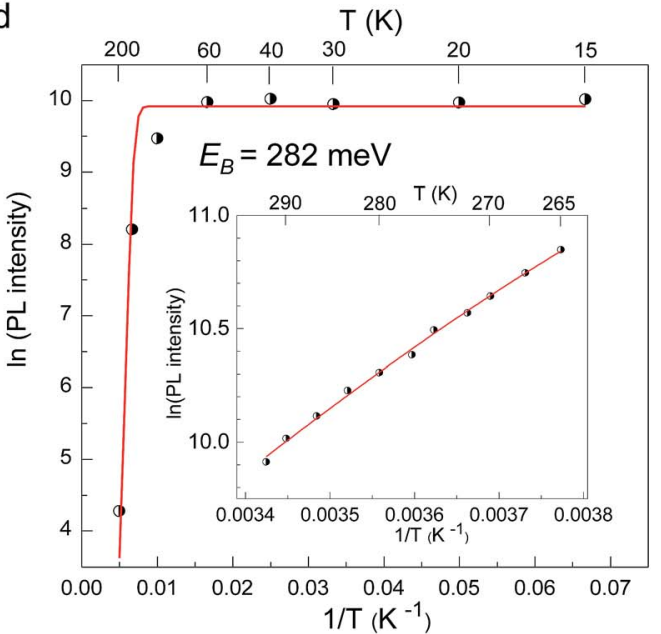

Fig. 2 (a) $\mathrm{PL}$ spectra of $2 \mathrm{D}$ layered $\mathrm{CH}_{3} \mathrm{CH}_{2} \mathrm{CH}_{2} \mathrm{CH}_{2} \mathrm{NH}_{3} \mathrm{Pbl}_{4}$ perovskite for temperatures from 13 to $300 \mathrm{~K}$. (b) $\mathrm{PL}$ peak energy vs. temperature, fitted using the Bose-Einstein oscillator model (dashed red curve). The inset show the FWHM as a function of temperature. (c) The optical and acoustic phonon energies as functions of temperature in the Bose-Einstein oscillator model. (d) PL intensity as a function of temperature. The exciton binding energy is $\sim 282 \mathrm{meV}$.

role in determining the electronic structure. ${ }^{41,47}$ The optical transitions in $2 \mathrm{D}$ perovskites thus stem from the $6 \mathrm{~s}$ to $6 \mathrm{p}$ transition in $\mathrm{Pb}^{2+}$, which is similar to that in $\mathrm{PbI}_{2}$. Because $\mathrm{Pb}(207)$ has a larger atomic mass than $\mathrm{I}(126)$, the $\mathrm{Pb}$ atoms undergo Bose-Einstein oscillation at a low frequency that induces acoustic phonons, whereas the I atoms predominantly exhibit high-frequency Bose-Einstein oscillations, resulting in optical phonons. The electron-phonon interactions critically depend on the amplitudes of the phonons and the corresponding coupling constants. Thus, the temperature dependence of the free-exciton emission energy $E_{\mathrm{g}}(T)$ should be related to that of both the optical phonon energy, $E_{\mathrm{OP}}(T)$, and the acoustic phonon energy, $E_{\mathrm{AP}}(T):^{39,40}$

$$
\begin{aligned}
& E_{\mathrm{OP}}(T)=A_{1}\left[\frac{2}{\exp \left(E_{1} / k_{\mathrm{B}} T\right)-1}+1\right], \\
& E_{\mathrm{AP}}(T)=A_{2}\left[\frac{2}{\exp \left(E_{2} / k_{\mathrm{B}} T\right)-1}+1\right],
\end{aligned}
$$

$$
E_{\mathrm{g}}(T)=E_{0}+E_{\mathrm{OP}}(T)+E_{\mathrm{AP}}(T),
$$

where $E_{1}$ and $E_{2}$ are the average energies of the Einstein oscillators corresponding to the optical and acoustic phonons, respectively; $A_{1}$ and $A_{2}$ describe the strength of the electronphonon interactions, if negative, indicate that the band gap energy decrease with increasing temperature; $k_{\mathrm{B}}$ and $T$ are the Boltzmann constant and temperature, respectively. Fig. $2 \mathrm{~b}$ shows the fit of the experimental PL peak energy data to a model based on two types of Bose-Einstein oscillators (red dashed curve). The $E_{0}$ value obtained by fitting the data is $\sim 2.39 \mathrm{eV}$. The average energies of the optical $\left(E_{1}\right)$ and acoustic $\left(E_{2}\right)$ phonons are $27.5 \mathrm{meV}$ and $0.028 \mathrm{meV}$, respectively, and $A_{1}$ and $A_{2}$ are $-32.3 \mathrm{meV}$ and $0.022 \mathrm{meV}$, respectively. Fig. 2c shows the energies of the optical and acoustic phonons as functions of temperature. The acoustic phonon function $E_{\mathrm{AP}}$ is positive and monotonically increases with increasing temperature, whereas the optical phonon function $E_{\mathrm{OP}}$ shows the opposite trend, monotonically decreasing as the temperature increases. 
Moreover, $\left|E_{\mathrm{OP}}\right|>\left|E_{\mathrm{AP}}\right|$. Thus, the total phonon function satisfies $\left(E_{\mathrm{AP}}+E_{\mathrm{OP}}\right)<0$, resulting in an excitonic energy $E_{\mathrm{g}}(T)$ is smaller than $E_{0}$ and shows a non-monotonic variation. Thus, the coherent lattice motion of the atoms in $2 \mathrm{D}$ layered $\mathrm{CH}_{3}$ $\left(\mathrm{CH}_{2}\right)_{3} \mathrm{NH}_{3} \mathrm{PbI}_{4}$ films below $150 \mathrm{~K}$ induces acoustic phonons, resulting in an increase in the PL peak energy. However, the outof-phase movements of the atoms in the lattice dominate above $150 \mathrm{~K}$, giving rise to optical phonons and consequently causing the PL peak energy to decrease. Therefore, the temperaturedependent behaviour of the acoustic and optical phonons results in the non-monotonic temperature variation of the PL peak energy. Free excitons are confined in the quantum-well structure of $2 \mathrm{D}$ layered $\mathrm{CH}_{3}\left(\mathrm{CH}_{2}\right)_{3} \mathrm{NH}_{3} \mathrm{PbI}_{4}$ perovskite, giving rise to a large exciton binding energy. Further analysis of the temperature dependence data yields insight into the freeexciton binding energy.

Fig. 2d shows the PL intensity as a function of $1 / T$ under laser excitation at $4.88 \mathrm{eV}$; the plot indicates that the PL intensity first gradually increases and then dramatically decreases as the temperature increases. Under steady-state excitation, the temperature dependence of the PL intensity can be expressed $\operatorname{as}^{48}$

$$
I(T)=\frac{I_{0}}{1+\eta \exp \left(-E_{\mathrm{B}} / k_{\mathrm{B}} T\right)},
$$

where $I(T)$ and $I_{0}$ are the PL intensities of $\mathrm{CH}_{3}\left(\mathrm{CH}_{2}\right)_{3} \mathrm{NH}_{3} \mathrm{PbI}_{4}$ at $T$ and $0 \mathrm{~K}$, respectively, and $E_{\mathrm{B}}$ is the exciton binding energy. By fitting the experimental data using eqn (6) (Fig. 2d) in the regions of 15-200 and 265-300 K, the exciton binding energy $E_{\mathrm{B}}$ is estimated to be $\sim 282 \mathrm{meV}$. This value is $\sim 14.8$ times larger than that of $3 \mathrm{D} \mathrm{CH}_{3} \mathrm{NH}_{3} \mathrm{PbI}_{4}(\sim 19 \mathrm{meV}),{ }^{49}$ suggesting that the $2 \mathrm{D}$ material can be utilized as active elements for excitonic devices, ${ }^{50,51}$ such as for excitonic energy transfer. ${ }^{52-54}$

$\mathrm{CH}_{3}\left(\mathrm{CH}_{2}\right)_{3} \mathrm{NH}_{3} \mathrm{PbI}_{4}$ exhibits excellent non-linear optical properties. A home-built two-photon optical microscope was used to investigate the TPPL of $\mathrm{CH}_{3}\left(\mathrm{CH}_{2}\right)_{3} \mathrm{NH}_{3} \mathrm{PbI}_{4}$ perovskite. ${ }^{55}$ Fig. 3 shows the one- and two-photon photoluminescence (OPPL and TPPL) spectra of the 2D layered $\mathrm{CH}_{3}\left(\mathrm{CH}_{2}\right)_{3} \mathrm{NH}_{3} \mathrm{PbI}_{4}$ films under pulsed laser excitation at 3.1 and $1.55 \mathrm{eV}$. The PL intensity shows a linear relationship with the excitation power
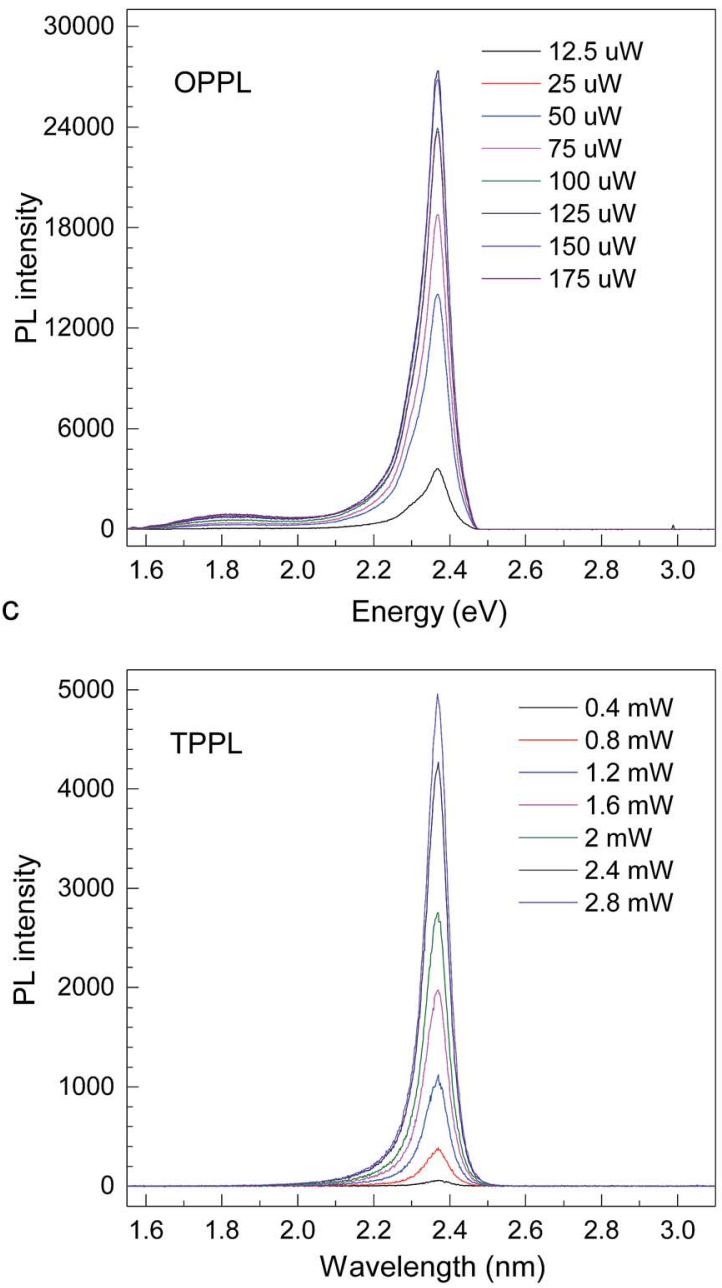

b
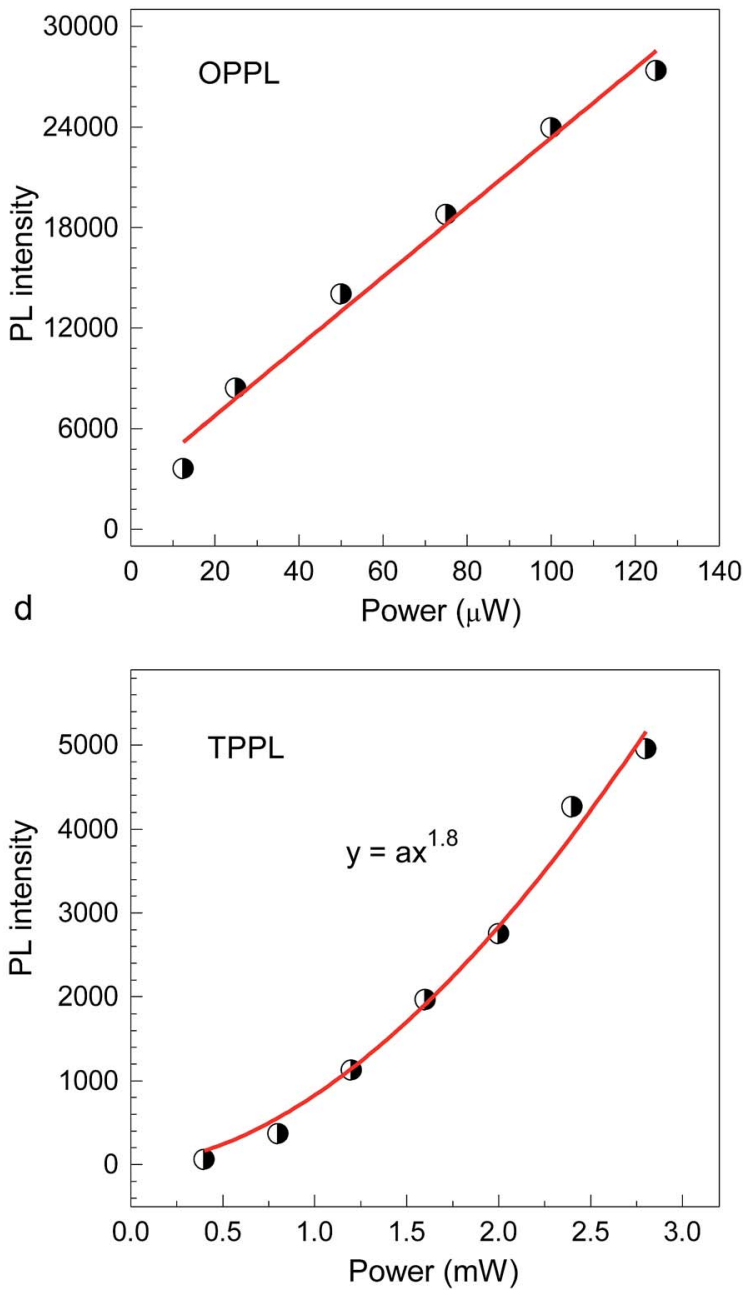

Fig. 3 ( $a$ and b) OPPL spectra and (c and d) TPPL spectra of $2 \mathrm{D}$ layered $\mathrm{CH}_{3} \mathrm{CH}_{2} \mathrm{CH}_{2} \mathrm{CH}_{2} \mathrm{NH}_{3} \mathrm{Pbl}_{4}$ perovskite films at room temperature. 
a

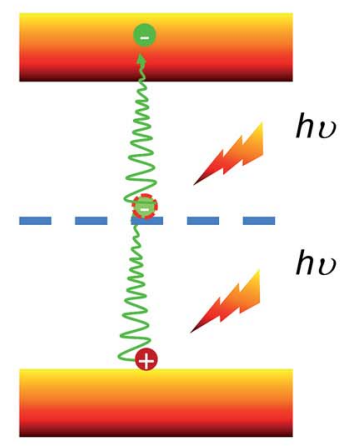

b

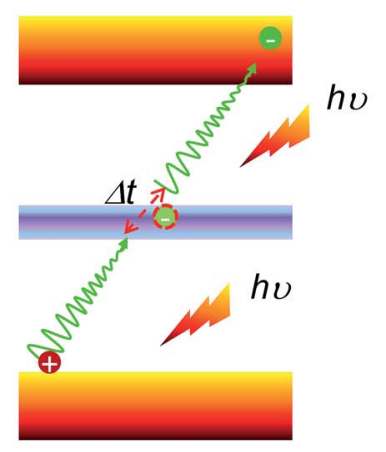

C

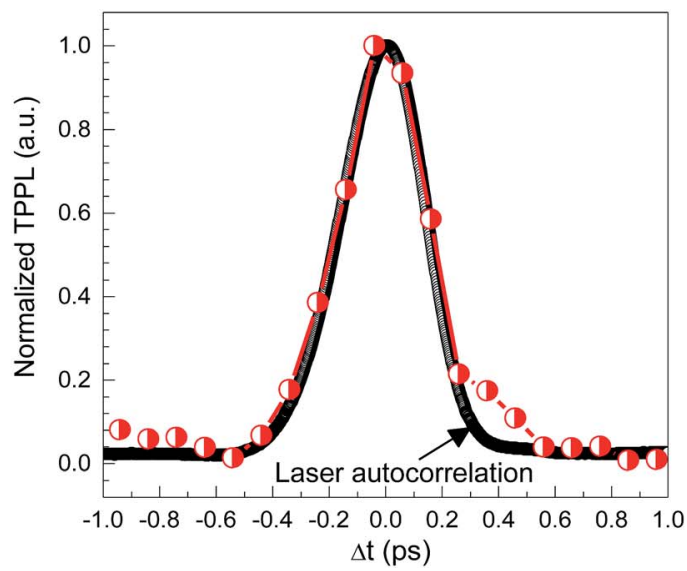

Fig. 4 (a and b) Schematic illustrations of two excitation mechanisms: (a) coherent two-photon absorption through a virtual state and (b) two sequential one-photon absorptions through real intermediate states. (c) TPEM measurement of 2D layered $\mathrm{CH}_{3} \mathrm{CH}_{2} \mathrm{CH}_{2} \mathrm{CH}_{2} \mathrm{NH}_{3} \mathrm{Pbl}$ perovskite (BAPI) at room temperature.

under optical pumping with $3.1 \mathrm{eV}$ (Fig. 3a and b). Under $1.55 \mathrm{eV}$ excitation, an exponential relationship between PL intensity and excitation power is observed, which can be well fitted using the function $y=a x^{1.8}$ (Fig. $3 \mathrm{c}$ and d), indicating the occurrence of TPPL. Considering the long tails of the absorption spectrum of the $2 \mathrm{D}$ layered $\mathrm{CH}_{3}\left(\mathrm{CH}_{2}\right)_{3} \mathrm{NH}_{3} \mathrm{PbI}_{4}$ films (Fig. 1c), two possible excitation mechanisms may be responsible for the TPPL, namely, a coherent two-photon absorption process or two sequential one-photon absorption processes. The schematic excitation diagrams of these processes are displayed in Fig. 4, respectively. In the coherent two-photon absorption model, two photons are absorbed simultaneously to drive a single electron from the VB into the CB via a virtual intermediate state (Fig. 4a). In the sequential one-photon absorption model, two photons are absorbed sequentially, mediated by a real intermediate state between the VB and CB (Fig. $4 \mathrm{~b}$ ).

To investigate the TPPL excitation mechanism of the $2 \mathrm{D}$ layered $\mathrm{CH}_{3}\left(\mathrm{CH}_{2}\right)_{3} \mathrm{NH}_{3} \mathrm{PbI}_{4}$ films, two-pulse emission modulation (TPEM) measurements were conducted to probe the correlated effects of two pulses on the observed PL emission. ${ }^{56}$ Two $1.55 \mathrm{eV}$ femtosecond laser pulses with similar power were focused onto a $2 \mathrm{D}$ layered $\mathrm{CH}_{3}\left(\mathrm{CH}_{2}\right)_{3} \mathrm{NH}_{3} \mathrm{PbI}_{4}$ film with a good spatial overlap. The TPPL intensity was recorded as a function of the time delay $(\Delta t)$ between the two laser pulses. In this configuration, the recorded TPPL emission has two possible origins: (1) two photons from the same laser excitation pulse and (2) two photons from different excitation pulses. It is easy to see that the contribution from the former process is independent of the time delay between two laser pulses, as the excitation photons originate from the same pulse. By contrast, the latter represents the cross-contribution of two individual laser pulses to the TPPL; thus, its contribution is maximal when the two pulses temporally overlap and decreases in intensity as they temporally separate. In the case of the coherent two-photon absorption model, the TPEM curve should show the same profile as that of the laser pulses because the emission originates from the simultaneous absorption of two photons through a virtual state. In the case of sequential one-photon excitations, the two one-photon excitation processes occur at the time scale of the lifetime of the real intermediate state; consequently, the TPEM dynamics should follow the lifetime of the intermediate state, similar to our previous reported TPPL excitation mechanism of gold nanorods ${ }^{56}$ As shown in Fig. 4c, the measured TPEM curve of $\mathrm{CH}_{3}\left(\mathrm{CH}_{2}\right)_{3} \mathrm{NH}_{3} \mathrm{PbI}_{4}$ perovskite exhibits a FWHM of $\sim 360 \mathrm{fs}$, which is consistent with the laser autocorrelation profile. These results suggest that the TPPL in $\mathrm{CH}_{3}\left(\mathrm{CH}_{2}\right)_{3} \mathrm{NH}_{3} \mathrm{PbI}_{4}$ perovskite is excited through the coherent two-photon absorption mechanism (Fig. 4a).

\section{Conclusions}

In 2D layered $\mathrm{CH}_{3}\left(\mathrm{CH}_{2}\right)_{3} \mathrm{NH}_{3} \mathrm{PbI}_{4}$ perovskite films, we observed a non-monotonic temperature variation of the PL peak energy in which the acoustic phonon energy exhibits a positive temperature variation, which is attributed to Bose-Einstein oscillation, whereas the optical phonon energy displays the opposite behaviour. The dielectric confinement effect due to the quantum-well structure of the material strengthens the Coulomb interaction between an electron and a hole, imparting the $\mathrm{CH}_{3}\left(\mathrm{CH}_{2}\right)_{3} \mathrm{NH}_{3} \mathrm{PbI}_{4}$ perovskite with a large exciton binding energy of $\sim 282 \mathrm{meV}$ and thus providing an opportunity to study the exciton dynamics. The nonlinear optical properties of TPPL in 2D layered $\mathrm{CH}_{3}\left(\mathrm{CH}_{2}\right)_{3} \mathrm{NH}_{3} \mathrm{PbI}_{4}$ perovskite were also observed, and we confirmed that the excitation is driven by a coherent two-photon absorption mechanism. The strong electronphonon interactions and large exciton binding energy in 2D layered $\mathrm{CH}_{3}\left(\mathrm{CH}_{2}\right)_{3} \mathrm{NH}_{3} \mathrm{PbI}_{4}$ perovskite suggest its potential for use for high-efficiency excitonic energy transfer in lighting and display applications.

\section{Author contributions}

B. P. and K. P. L. conceived and supervised the experiment. B. P. synthesized $\mathrm{CH}_{3}\left(\mathrm{CH}_{2}\right)_{3} \mathrm{NH}_{3} \mathrm{PbI}_{4}$ perovskites. H. Z. and Q. X. 
carried out two photon PL measurements and TPEM measurement. J. L., Y. L., L. B., H. L., J. X., L. D., L. Z., X. W. carried out the absorption and low temperature PL measurement. All authors discussed the results and wrote the manuscript.

\section{Acknowledgements}

B. P. acknowledges financial support from National Science Foundation of China (51602040) and Scientific Research Foundation for new teachers of University of Electronic Science and Technology of China (ZYGX2015KYQD057, A03013023601007). K. P. L. thanks A* star-DST project number 1425203139 "Flexible and high performance perovskite based solar cells on grapheme electrodes".

\section{Notes and references}

1 G. Xing, N. Mathews, S. Sun, S. S. Lim, Y. M. Lam, M. Grätzel, S. Mhaisalkar and T. C. Sum, Science, 2013, 342, 344-347.

2 M. A. Green, A. Ho-Baillie and H. J. Snaith, Nat. Photonics, 2014, 8, 506-514.

3 J.-H. Im, I.-H. Jang, N. Pellet, M. Grätzel and N.-G. Park, Nat. Nanotechnol., 2014, 9, 927-932.

4 A. Kojima, K. Teshima, Y. Shirai and T. Miyasaka, J. Am. Chem. Soc., 2009, 131, 6050-6051.

5 M. Liu, M. B. Johnston and H. J. Snaith, Nature, 2013, 501, 395-398.

6 A. Marchioro, J. Teuscher, D. Friedrich, M. Kunst, R. van de Krol, T. Moehl, M. Gratzel and J.-E. Moser, Nat. Photonics, 2014, 8, 250-255.

7 C. S. Ponseca, T. J. Savenije, M. Abdellah, K. Zheng, A. Yartsev, T. Pascher, T. Harlang, P. Chabera, T. Pullerits, A. Stepanov, J.-P. Wolf and V. Sundström, J. Am. Chem. Soc., 2014, 136, 5189-5192.

8 S. D. Stranks, G. E. Eperon, G. Grancini, C. Menelaou, M. J. P. Alcocer, T. Leijtens, L. M. Herz, A. Petrozza and H. J. Snaith, Science, 2013, 342, 341-344.

9 M. M. Lee, J. Teuscher, T. Miyasaka, T. N. Murakami and H. J. Snaith, Science, 2012, 338, 643-647.

10 Y. Hu, J. Schlipf, M. Wussler, M. L. Petrus, W. Jaegermann, T. Bein, P. Müller-Buschbaum and P. Docampo, ACS Nano, 2016, 10, 5999-6007.

11 Best Research-Cell Efficiencies, http://www.nrel.gov/ncpv/ images/efficiency_chart.jpg, 2016.

12 N. J. Jeon, J. H. Noh, W. S. Yang, Y. C. Kim, S. Ryu, J. Seo and S. I. Seok, Nature, 2015, 517, 476-480.

13 J. Burschka, N. Pellet, S.-J. Moon, R. Humphry-Baker, P. Gao, M. K. Nazeeruddin and M. Gratzel, Nature, 2013, 499, 316319.

14 Y. Wang, X. Li, J. Song, L. Xiao, H. Zeng and H. Sun, Adv. Mater., 2015, 27, 7101-7108.

15 L. Protesescu, S. Yakunin, M. I. Bodnarchuk, F. Krieg, R. Caputo, C. H. Hendon, R. X. Yang, A. Walsh and M. V. Kovalenko, Nano Lett., 2015, 15, 3692-3696.

16 S. Sun, D. Yuan, Y. Xu, A. Wang and Z. Deng, ACS Nano, 2016, 10, 3648-3657.
17 J. Song, J. Li, X. Li, L. Xu, Y. Dong and H. Zeng, Adv. Mater., 2015, 27, 7162-7167.

18 W. Niu, A. Eiden, G. Vijaya Prakash and J. J. Baumberg, Appl. Phys. Lett., 2014, 104, 171111.

19 S. T. Ha, X. Liu, Q. Zhang, D. Giovanni, T. C. Sum and Q. Xiong, Adv. Opt. Mater., 2014, 2, 838-844.

20 Q. Zhang, S. T. Ha, X. Liu, T. C. Sum and Q. Xiong, Nano Lett., 2014, 14, 5995-6001.

21 Q. Liao, K. Hu, H. Zhang, X. Wang, J. Yao and H. Fu, Adv. Mater., 2015, 27, 3405-3410.

22 J. Liu, Y. Xue, Z. Wang, Z.-Q. Xu, C. Zheng, B. Weber, J. Song, Y. Wang, Y. Lu, Y. Zhang and Q. Bao, ACS Nano, 2016, 10, 3536-3542.

23 L. Dou, A. B. Wong, Y. Yu, M. Lai, N. Kornienko, S. W. Eaton, A. Fu, C. G. Bischak, J. Ma, T. Ding, N. S. Ginsberg, L.-W. Wang, A. P. Alivisatos and P. Yang, Science, 2015, 349, 1518-1521.

24 X. Hong, T. Ishihara and A. V. Nurmikko, Phys. Rev. B: Condens. Matter Mater. Phys., 1992, 45, 6961-6964.

25 D. B. Mitzi, J. Chem. Soc., Dalton Trans., 2001, 1-12, DOI: 10.1039/b007070j.

26 C. C. Stoumpos, D. H. Cao, D. J. Clark, J. Young, J. M. Rondinelli, J. I. Jang, J. T. Hupp and M. G. Kanatzidis, Chem. Mater., 2016, 28, 2852-2867.

27 K. Gauthron, J. S. Lauret, L. Doyennette, G. Lanty, A. Al Choueiry, S. J. Zhang, A. Brehier, L. Largeau, O. Mauguin, J. Bloch and E. Deleporte, Opt. Express, 2010, 18, 5912-5919. 28 D. B. Mitzi, Chem. Mater., 1996, 8, 791-800.

29 D. B. Mitzi, Inorg. Chem., 2000, 39, 6107-6113.

30 D. B. Mitzi, D. R. Medeiros and P. R. L. Malenfant, Inorg. Chem., 2002, 41, 2134-2145.

31 S.-T. Ha, C. Shen, J. Zhang and Q. Xiong, Nat. Photonics, 2016, 10, 115-121.

32 L. Etgar, P. Gao, Z. Xue, Q. Peng, A. K. Chandiran, B. Liu, M. K. Nazeeruddin and M. Grätzel, J. Am. Chem. Soc., 2012, 134, 17396-17399.

33 Y. P. Varshni, Physica, 1967, 34, 149-154.

34 J. Zhang, D. Li, R. Chen and Q. Xiong, Nature, 2013, 493, 504508.

35 S. Tongay, J. Zhou, C. Ataca, K. Lo, T. S. Matthews, J. Li, J. C. Grossman and J. Wu, Nano Lett., 2012, 12, 5576-5580.

36 Y. J. Lu, J. Kim, H. Y. Chen, C. H. Wu, N. Dabidian, C. E. Sanders, C. Y. Wang, M. Y. Lu, B. H. Li, X. G. Qiu, W. H. Chang, L. J. Chen, G. Shvets, C. K. Shih and S. Gwo, Science, 2012, 337, 450-453.

37 J. S. Ross, S. Wu, H. Yu, N. J. Ghimire, A. M. Jones, G. Aivazian, J. Yan, D. G. Mandrus, D. Xiao, W. Yao and X. Xu, Nat. Commun., 2013, 4, 1474.

38 J. Huang, T. B. Hoang and M. H. Mikkelsen, Sci. Rep., 2016, 6, 22414.

39 J. Bhosale, A. K. Ramdas, A. Burger, A. Muñoz, A. H. Romero, M. Cardona, R. Lauck and R. K. Kremer, Phys. Rev. B: Condens. Matter Mater. Phys., 2012, 86, 195208.

40 V. D'Innocenzo, G. Grancini, M. J. P. Alcocer, A. R. S. Kandada, S. D. Stranks, M. M. Lee, G. Lanzani, H. J. Snaith and A. Petrozza, Nat. Commun., 2014, 5, 3586. 
41 T. Ishihara, J. Takahashi and T. Goto, Phys. Rev. B: Condens. Matter Mater. Phys., 1990, 42, 11099-11107.

42 A. Göbel, T. Ruf, M. Cardona, C. T. Lin, J. Wrzesinski, M. Steube, K. Reimann, J. C. Merle and M. Joucla, Phys. Rev. B: Condens. Matter Mater. Phys., 1998, 57, 15183-15190.

43 S. Ozaki and Y. Horikoshi, J. Appl. Phys., 2014, 115, 053526.

44 M. Cardona and M. L. W. Thewalt, Rev. Mod. Phys., 2005, 77, 1173-1224.

45 T. Kenichiro, T. Takayuki, K. Takashi, U. Kenichi, E. Kazuhiro, U. Tsutomu, A. Keisuke, U. Kazuhito and M. Noboru, Jpn. J. Appl. Phys., 2005, 44, 5923.

46 J. Even, L. Pedesseau, M. A. Dupertuis, J. M. Jancu and C. Katan, Phys. Rev. B: Condens. Matter Mater. Phys., 2012, 86, 205301.

47 D. Giovanni, W. K. Chong, H. A. Dewi, K. Thirumal, I. Neogi, R. Ramesh, S. Mhaisalkar, N. Mathews and T. C. Sum, Sci. Adv., 2016, 2, e1600477.

48 M. Leroux, N. Grandjean, B. Beaumont, G. Nataf, F. Semond, J. Massies and P. Gibart, J. Appl. Phys., 1999, 86, 3721-3728.
49 G. Xing, N. Mathews, S. S. Lim, N. Yantara, X. Liu, D. Sabba, M. Grätzel, S. Mhaisalkar and T. C. Sum, Nat. Mater., 2014, 13, 476-480.

50 B. Peng, G. Yu, X. Liu, B. Liu, X. Liang, L. Bi, L. Deng, T. C. Sum and K. P. Loh, 2D Mater., 2016, 3, 025020.

51 B. Peng, G. Yu, Y. Zhao, Q. Xu, G. Xing, X. Liu, D. Fu, B. Liu, J. R. S. Tan, W. Tang, H. Lu, J. Xie, L. Deng, T. C. Sum and K. P. Loh, ACS Nano, 2016, 10, 6383-6391.

52 B. Peng, Q. Zhang, X. F. Liu, Y. Ji, H. V. Demir, C. H. A. Huan, T. C. Sum and Q. H. Xiong, ACS Nano, 2012, 6, 6250-6259.

53 B. Peng, X. Lu, S. Chen, C. H. A. Huan, Q. Xiong, E. Mutlugun, H. V. Demir and S. F. Yu, Nano Res., 2016, 9, 549-559.

54 B. Peng, Z. Li, E. Mutlugun, P. L. Hernandez Martinez, D. Li, Q. Zhang, Y. Gao, H. V. Demir and Q. Xiong, Nanoscale, 2014, 6, 5592-5598.

55 M. Garai, T. Zhang, N. Gao, H. Zhu and Q.-H. Xu, J. Phys. Chem. C, 2016, 120, 11621-11630.

56 X.-F. Jiang, Y. Pan, C. Jiang, T. Zhao, P. Yuan, T. Venkatesan and Q.-H. Xu, J. Phys. Chem. Lett., 2013, 4, 1634-1638. 